\title{
350 years of hyperbaric medicine: historic, physiopathologic and therapeutic aspects
}

\author{
Oswaldo Huchim 1 , Fernando Rivas-Sosa², Normando Rivera-Canul ${ }^{\beta}$ and Nina Méndez-Domínguez ${ }^{3}$ \\ ${ }^{1}$ Unidad Experimental Marista; ${ }^{2}$ Hospital General O'Horan; ${ }^{3}$ Universidad Marista de Mérida. Mérida, Yucatán, Mexico
}

\begin{abstract}
The early use of hyperbaric therapy started with the quest to relieve respiratory problems among inhabitants of large cities during the industrial revolution, and from this, we have explored the benefits of treatment with hyperbaric oxygen in different areas of medicine. With the advances of the medical sciences, our knowledge concerning the therapies with hyperbaric oxygenation certainly has broadened and hyperbaric medicine still intrigues the contemporary medical researchers that are in seek of improve the quality of life of their patients.
\end{abstract}

KEY WORDS: Hyperbaric oxygenation. Decompression sickness. Atmospheric pressure. History of medicine. Therapeutics. Physiopathology.

\section{Introduction}

Hyperbaric oxygenation provides a therapy mainly intended for the treatment of decompression sickness, generated by changes in environmental pressure, as it occurs in the case of diving and aeronautics. In a second place, hyperbaric oxygenation is used for cosmetic purposes, owing to its popularized use to counteract cell aging. However, hyperbaric medicine offers much more than this and is, with no doubt, a useful resource during the comprehensive treatment of various pathologies that involve ischemic processes.

Hyperbaric oxygenation can have several applications both in emergency situations and to potentiate the effect of comprehensive therapies in chronic pathologies or acute events' sequels. The purpose of the present article is to review the history and pathophysiogenic mechanisms involved in hyperbaric therapy.

\section{Background}

Oxygen, as other gases, reacts with pressurization and depressurization; when oxygen concentration increases owing to its solubility under pressure, its diffusion gradient is increased, which enables deep penetration into tissues. It is by this principle that the treatment with hyperbaric oxygenation helps in the repair of poorly perfused, hypoxic, ischemic, infarcted or necrotic tissue areas. Better oxygenation enables the triggering of the tissue recovery process and, in addition, it facilitates reperfusion and angiogenesis.

Hyperbaric oxygen effect on the treatment of different health conditions could be known thanks to experiments carried out in hyperbaric chambers with diverse animal models'.

Pathologic conditions involving ischemia improve with hyperbaric oxygen treatment, since this method consists in $100 \%$ oxygen inhalation inside a hyperbaric chamber under pressure, usually at between 2 and

\section{Correspondence:}

Nina Méndez-Domínguez

Periférico Norte Tablaje Catastral 13941 Carretera

Mérida- Progreso

Date of reception: 12-12-2016

Date of acceptance: 04-01-2017

C.P. 97300, Mérida, Yuc., México

E-mail: ninuxka@hotmail.com
DOI://dx.doi.org/10.24875/GMM.M18000102
Gac Med Mex. 2017;153:854-860

Contents available at PubMed www.gacetamedicademexico.com 
3 atmospheres. As in any treatment, hyperbaric chamber sessions imply dosing both in terms of pressure and in the number and duration of sessions. Dosing should be indicated according to the medical condition to be treated, its seriousness and time of evolution ${ }^{2,3}$.

There are two types of hyperbaric chambers: monoplace or multiplace. While in the monoplace chambers pressurization occurs by means of oxygen and pressure increase is systemic, multichamber chambers are pressurized with air and oxygen is supplied with a facemask, a helmet or and endotracheal tube, as appropriate ${ }^{4}$.

\section{Methodology}

A review was conducted from the $18^{\text {th }}$ century on, where historical texts and manuscripts, digitalized by university libraries, were analyzed. Documents related to topics associated with barometric, climatic and topographic characteristics of health and disease processes were included, but also the conceptual bases for the knowledge of the physiological properties of gases in the human body. The search for articles published since the $18^{\text {th }}$ century was performed in PubMed and included the terms "caisson disease" or "hyperbaric oxygen therapy", with 651 registries being obtained, among which those addressing different diseases or syndromes treated with hyperbaric oxygen therapy were selected, with those that were more recent and had the highest level of available evidence (articles based on expert opinions have the lowest level of evidence, followed by case reports, original articles, descriptive reviews, systematic reviews and meta-analyses) being preferred to be included in the present review.

\section{Physical and physiological bases of hyperbaric oxygenation therapy}

Hyperbaric oxygen therapy effects are based on biochemical processes that are triggered by hyperoxygenation and by physiological effects that are favored according with physical laws and with the properties of gases.

In the human body, oxygen is largely transported by the blood tissue, bound to hemoglobin. In addition, a proportion of oxygen is transported as a solution, and this proportion of oxygen can be increased and improve tissue oxygenation according to the principles outlined in Henry's law ${ }^{4,5}$.
Henry's law establishes that the amount of gas dissolved in a fluid or tissue is proportional to the partial pressure of said gas in contact with the fluid or tissue. This is the basis to understand the growing pressures of oxygen in the tissue when hyperbaric oxygen therapy is received. This law also has implications in the pathophysiology of decompression sickness, since it affects inert gases (especially nitrogen) tissue concentrations as well, which generates effects on the concentration of said gas in the presence of barometric changes, thus eliciting an arterial embolism if reuptake in solution is not achieved ${ }^{5-7}$. At room temperature, oxygen is at a concentration of $97 \%$. When breathing normobaric oxygen, oxygen arterial pressure is $100 \mathrm{mmHg}$, while its tissue pressure is $55 \mathrm{mmHg}$, and in each liter of blood, there are approximately $3 \mathrm{~mL}$ of oxygen available. When breathing $100 \% \mathrm{~m}$ oxygen at 3 absolute atmospheres, oxygen arterial and tissue pressures increase to 2000 and $500 \mathrm{mmHg}$, respectively, thus allowing that for each liter of blood there are $60 \mathrm{~mL}$ of oxygen available. In response to this high amount of oxygen available, body tissues could potentially remain oxygenated even in the absence of hemoglobin-transported oxygen. This way, hyperbaric oxygenation allows for those zones of damaged tissue to be oxygenated, even if the passage of blood is obstructed or when red blood cells are incompetent to transport oxygen by itself, as in the case of poisoning with carbon monoxide and anemia gravis; in addition, it enables oxygenation independently of hemoglobin transport in cases where there is microvascular damage, as it occurs in diabetes ${ }^{8-10}$.

Oxygen captured by respiration also varies during hyperbaric chamber treatment since, during the descent to deepness, oxygen intra-alveolar pressure increases; this occurs as a physiological response Boyle's law and Dalton's law. Dalton's law outlines that, at constant temperature, the pressure of a gas is inversely proportional to its volume, whereas Dalton's law states that, in a mixture of gases, each element exerts a pressure that id proportional to its fraction of total volume; these laws explain the effect of oxygen partial pressure and its intra-alveolar disposition ${ }^{11-14}$.

In infections, free-radicals act oxidizing proteins and membrane lipids, which damages the DNA and bacterial metabolic functions. Hyperbaric oxygen therapy increases free radical concentrations, and this is why it is particularly effective against anaerobic microorganisms by promoting the oxygen-dependent 
peroxidase system; this system is used by leukocytes to attack bacteria. Furthermore, it also improves the transport of oxygen-dependent antimicrobials, allowing their penetration through the cell walls, thus contributing to and potentiating their efficcay ${ }^{15-18}$.

In tissue lesions, particularly in compartmental syndromes, compression lesions, flaps and lacerations, leukocytes tend to direct and adhere to damaged tissues to release free radicals and proteases during reperfusion but, paradoxically, this process can lead to pathological vasoconstriction causing tissue destruction mediated by hypoxia. Similar process occurs during the neuronal and cardiac ischemia-reperfusion process during infarctions. There is evidence that hyperbaric oxygen reduces leukocyte adherence and post-ischemic vasoconstriction, which results in better perfusion of ischemic areas, while favoring oxygenation even in the absence of good perfusion. Another mechanism by means of which hyperbaric chamber treatment favors the healing of ischemia-perfusion lesions is by amplifying oxygen gradients in the periphery of ischemic lesions, thereby promoting angiogenesis, which requires the formation of collagen matrix, which in turn is oxygen-dependent. Finally, hyperbaric oxygen therapy enables blood flow redistribution owing to gradient differences, which alleviates edema generated in damaged tissues, thus reducing pain and improving the function ${ }^{19-23}$.

It is mainly because of the physical laws here exposed, and the physiological and pathophysiological pathways involved, that hyperbaric medicine offers benefits for health conditions involving said pathways.

\section{History}

The birth of hyperbaric medicine goes back, as every finding, to observation and analysis, in this case, of the difference in physiological and health aspects of human populations living in the different geographical zones ${ }^{24-26}$.

Arbuthnot, circa 1655, mentioned the relationship between humidity and the efficiency of air inspired in different places of the world. For the decade of 1660 , in England, the Industrial Revolution and the emission of gases by factories with machines operating with steam and carbon generated concerns in men of science and doctors of those days. It was since that moment that a growing awareness was born that air pollution was having effects on human health and wellbeing. Authors such as Digby, in 1658, indicated among their therapeutic recommendations moving out from London to those who had "weak lungs, but high income", to avoid carbon-polluted air ${ }^{27,28}$.

Nathaniel Henshaw, and English doctor and clergyman, member of the then nascent Royal Society, aware of the atomist theory, of meteorology, which was founding its bases in those days, and integrating knowledge of atmospheric science with the principles of Boyle's law, was able to explain the differences he had identified in the status of health of people living outside the cities, and believed he had found a relationship between the weather and altitude of the place of residence and human health and disease profiles $^{13,25}$.

Henshaw, circa 1662, constructed a domicilium, which consisted of a chamber with a pressurized bellows with a mechanism of piped with valves that, when manipulated, allowed or limited the passage of the air contained in the chamber, by means of which he could control the chamber inner pressure. In this primitive hyperbaric chamber, the first treatments based on hyperbaric air were offered with the purpose to provide poor air to the patients and treat tissues with purulent secretions or "miasmas". Thomas Sprat addressed Henshaw's work in his book on the knowledge generated by the Royal Society, in $1734^{24,29,30}$.

Another study of the epoch with important repercussions in the development of hyperbaric oxygenation was the one by Joseph Black in 1750, who, in assays with mice, isolated common air carbon monoxide. By 1772, Rutherford discovered nitrogen, and later, in 1774 , Priestly was the first one to find and leave a written report about his transcendent discovery: oxygen ${ }^{29,31}$.

Originally, Priestly was trying to generate "dephlogisticated air", since in his epoch it was thought that this way the "flammable" characteristics would be removed from the air. This belief was based on the "phlogiston theory", which in turn was based on the flammable properties of a hypothetical substance that was thought to be part of common air. Thanks to Priestly, the existence of phlogiston could be discarded, this way preparing the way for pneumatic chemistry. According to his registries, when experimenting with a murid model, the mouse managed to recover from an aggression with fire "much better" than if it would have breathed common air. Subsequently, Lavoisier was the first one to name oxygen and to describe its role on combustion, which may have discouraged physicians of his time about the use of said gas, in spite of the beneficial effects described by 
Priestly. In 1794, the first hyperbaric oxygen therapy center was reported ${ }^{32,33}$.

It is probable that the first hermetically sealed was the idea of Cochrane in 1830, wit it was patented until 1839 by Trigger, who designed it to avoid decompression sickness in French miners, and hence the chambers were known with their French name caisson. In 1834, Williams defined the "caisson disease", caused by barometric changes in high places and deep places, which generate the formation of bubbles and air embolism, defining it as divers' disease in his aerotherapeutics treaty, which addresses health and atmospheric pressure; planes for the manufacturing of chambers are therein included. In 1857, Paul Bernard described oxygen affinity for hemoglobin, with the demand for hyperbaric oxygenation services in Europe and the USA being triggered on that epoch. These services were initially provided to heal lesions, cure infections and improve the respiratory function, and immediately they became spaces for cosmetic care, and were even frequented by singers to preserve their tone of voice. In his text, he included the diagrams and plans of the chambers available on his epoch, as well as their functioning $1,32,34-38$.

The first construction of a chamber for laborers working in the construction of a bridge goes back to 1859 in Rochester, England, by Wright and Hudges. The track for the subway and the Hudson River Bridge in the USA started with the construction of the main tunnel in 1872 by $A$. Roebling. Both Brooklyn bridge granite foundations were built by laborers who descended in wooden platforms, submerging to up to 44 feet on the Brooklyn side and 78 feet on the New York side. Initially, laborers descended without taking pressurization into account, but serious consequences were soon to be observed owing to decompression sickness. In that moment, little was known about the risks of working under that conditions, and more than 100 workers suffered decompression sickness. Washington Roebling himself experienced a gas embolism that left him partially paralyzed for the rest of his life. When this problem was identified, boxes started being used instead of platforms for the descent. The boxes consisted of chambers or compartments, each one with different pressure, which enabled the individual to gradually pass from one to another, maintaining the doors hermetically closed, and thus avoid abrupt barometric changes that lead to decompression. Brooklyn bridge doctor, Adam Smith, picked up the term caisson disease and defined a preemptive technique and the decompression cases in 1871 and
1873, describing manifestations such as epigastric pain and neurological involvement. On May 24, 1883, Emily Roebling took the first stroll on the finished bridge with a rooster as a symbol of victory; this marked the end of the Brooklyn bridge construction and the beginning of the construction of increasingly complex hyperbaric chambers ${ }^{38-41}$.

Between 1904 and 1940, different works related to decompression sickness were published, with body fat, and hence obesity, being identified as a risk factor; in addition, the tissue damage caused by decompression was described according to the type of affected organs, with hyperbaric oxygen therapeutic effect being emphasized. In 1937, Behnke and Shaw successfully treated decompression sickness and subsequently carbon monoxide poisoning; in those days, the most prominent was the one of Cunningham, in Kansas, registered in 1952. As of 1956, there was a resurgence of hyperbaric medicine, with temperature control inside hyperbaric chambers, which enabled oxygenating the patients and keeping them warm during heart surgeries for acute processes, and even congenital heart disease repair. Between 1960 and 1977, an estimate of 187 open heart surgeries were performed, which is so far the only approved indication for the use of hyperbaric therapy ${ }^{42-47}$.

Owing to the interest on standardizing and reaching an agreement on the uses of hyperbaric oxygen, in the decade of 1970, the Undersea and Hyperbaric Medical Society (UHMS) was formed, which is the one that currently issues guidelines with regard to this therapy ${ }^{4}$.

By the end of the $20^{\text {th }}$ century, excessive caution owing to the lack of knowledge about the real mechanisms operating in hyperbaric therapy was thought to be the cause of its underuse in cases where it certainly might offer benefits to patients, and by 1990 , the body of evidence on its use was rapidly growing, thus enabling a better understanding of hyperbaric therapy mechanism of action and potential benefits. For the first decade of the $21^{\text {th }}$ century, given the concerns of doctors about the use of hyperbaric therapy due to the controversy that had been generated, the UHMS issued a list of the 13 approved uses for hyperbaric therapy. Even when it is true that there are pathophysiological processes where hyperbaric oxygen mechanism of action is still poorly known, the health conditions where hyperbaric oxygen therapy has been employed in hypobaric medicine modern epoch will be described next ${ }^{48,49}$. 


\section{Background of treatment with hyperbaric oxygen}

The growing population with overweight, obesity, dyslipidemia and diabetes mellitus often develops sequels, and many of them are derived from hypoperfusion and peripheral neuropathy. Owing to the lack of adequate microcirculation and innervation in the extremities, diabetes mellitus often generates the formation of ulcers known as "diabetic necrobiosis". It is described in scientific literature that glycemic imbalance-derived ulcers can be alleviated and even healed with a comprehensive treatment that involves sessions with oxygen in the hyperbaric chamber ${ }^{50-54}$.

In addition, hyperbaric oxygen often improves reperfusion, which favors angiogenesis even in small arteries, such as the retinal artery, the flow of which is commonly affected by diabetes; therefore, the hyperbaric chamber can offer benefits to patients with retinopathy of diabetic and non-diabetic etiology, as well as with retinitis pigmentosa ${ }^{55-57}$.

Such as hyperbaric oxygen improves oxygenation and favors circulation in small areas of the body, it has also been shown to be effective in the ear, helping to the recovery of two important functions that occur in the auricular area: hearing and balance. This has been found both in people with hearing acuity deterioration and in those who suffer from tinnitus ${ }^{58-61}$.

By improving perfusion and favoring some neurosensory aspects, hyperbaric oxygen therapy has been found to be useful in the recovery of patients who suffer atherosclerotic strokes, as well as in those who suffer neonatal hypoxia-related cerebral palsy ${ }^{62-63}$. In certain more complex conditions, as it is the case of Parkinson disease and carbon monoxide poisoning, cognitive function has been able to be improved in subjects who have suffered this type of damage ${ }^{64-66}$. In general, it provides benefits to patients who suffer damage to the nervous system, even in the case of viral neuropathies, such as those generated by the herpes zoster virus, or in cases where cerebral damage of the recurrent and chromic type, or caused by brain tumors. Hyperbaric oxygen therapy has shown positive effects on the quality of life and function of pediatric patients with disorders of the autistic spectrum ${ }^{65-69}$.

Hyperbaric oxygen benefits have been explored in the oncological area, with good results being found as a treatment concomitant with radiotherapy, chemotherapy or phototherapy, and after tumor-resection therapies, including mastectomy ${ }^{70,71}$. These hyperbaric oxygen effects are directly associated with the capacity to regenerate damaged tissues or in healing process; it is precisely because of this that it is also useful in the closure of accident-derived postoperative flaps, even including scalp closure in at least one individual who suffered the detachment of this area of tissue ${ }^{72,73}$. In addition, an improvement in bladder function has been found in patients with hemorrhagic cystitis secondary to radiotherapy treatment ${ }^{74}$.

Soft tissues damaged by different aggressions can show an important improvement with the hyperbaric chamber treatment as well, even if there are data consistent with infection or gangrene, or if the latter is of the gas type and generates compartmental syndrome or fascitis ${ }^{75-77}$. In cardiac tissue, hyperbaric oxygen therapy has served to recover ischemic zones in infarctions, since it favors post-ischemia-reperfusion oxygenation. The same favorable effect of hyperbaric oxygenation that has been observed in the myocardium has also been seen in pulmonary tissue ${ }^{78,79}$.

In bone tissue, the effectiveness of hyperbaric oxygen has been previously shown in bone lesions and as co-adjuvant in cardiothoracic surgery with sternotomy, as well as in osteonecrosis secondary to surgery-related trauma or to the consumption of bisphosphonates ${ }^{68,80}$.

In some conditions, either acute or chronic, where toxins that are poisonous to the body need to be cleared, treatment in the hyperbaric chamber is useful; such is the case of carbon monoxide poisoning, which may be generated by exposure to emissions of motor vehicles that use gasoline, just to give an example, or by venom inoculated by venomous animals, such as snakes ${ }^{81,82}$.

Finally, hyperbaric oxygenation beneficial effects have been reported in hematologic treatments, where it favors oxygenation and improves blood circulation, as it occurs in cases of severe anemia and in blood dyscrasias, such as purpura fulminans ${ }^{83-85}$.

Its experimental use for the treatment of certain types of infertility has been limited so far, although it has shown promising results ${ }^{86}$.

\section{Discussion}

In the light of the review regarding the history of hyperbaric chambers and the use of hyperbaric oxygen with therapeutic purposes, it can be suggested that the physical, physiological and pathophysiological bases support its use in different morbid processes. Hyperbaric medicine is a field of science that has not yet been 
fully explored, and although its use in many particular conditions is not supported by evidence from randomized, controlled clinical trials concluding that the benefit of this treatment is significantly superior to others in statistical terms, it is also true that the effectiveness of its use in pathological processes involving hypoperfusion, infection, ischemia or infarction, either acutely or chronically, has not been scientifically ruled out.

The effectiveness of hyperbaric oxygen should, in our opinion, be evaluated as a co-adjuvant therapy in the treatment of people with pathologies involving hypoperfusion, infection, ischemia or infarction processes, regardless of the etiological nature that has generated said morbid state, since if its effectiveness is tried to be assessed disease by disease, this type of therapy will end up being unnecessarily underused, since, if properly used, it can allow patients healing in shorter time, having less sequels or recovering aspects as important as sensitivity or function, which will directly impact on patients' quality of life, socialization and productivity.

An aspect that potentially can underlie hyperbaric oxygen therapy underuse in different settings is the cost it implies for insurance companies, which limit their right-holders access to hyperbaric oxygen therapy arguing the lack of evidence of its effectiveness for the specific condition of each insured. A possible solution to this conflict of interests might arise if hyperbaric oxygen therapy indications were not specific for a disease, but for syndromes and pathological processes involving hypoxia, hypoperfusion, infection, ischemia or infarction; this way, the benefits of this therapy could be offered to patients meeting these criteria. This could even be considered an extra benefit that would position insurance companies in advantage over competitors, by offering therapies their competition usually refuses.

\section{Conclusion}

As medical science advances, our knowledge regarding hyperbaric oxygen therapy will with no doubt grow, and this is why hyperbaric medicine remains a niche for clinical practice and research, which at 350 years of its initiation maintains the interest of contemporary medical researchers who are looking to improve the quality of life of their patients.

\section{Conflicts of interests}

The authors of the present work have no commercial links or conflicts of interests to declare.

\section{References}

1. Edwards ML. Hyperbaric oxygen therapy. Part 1: history and principles. Vet Emerg Crit Care. 2010;20:284-8.

2. Shahriari $A$, Khooshideh $M$, Heidari M. Diseases treated with hyperbaric oxygen therapy; a literature review. Med Hypothesis. 2014;1(1).

3. Hampson NB. Hyperbaric oxygen therapy: 2003 Committee Report. Undersea and Hyperbaric Medical Society; 1999

4. Gill A, Bell CN. Hyperbaric oxygen: its uses, mechanisms of action and outcomes. QJM. 2004;97:385-95.

5. Boyle R. LXXXII. The solubility of radium emanation. Application of Henry's law at low partial pressures. The London, Edinburgh, and Dublin Philosophical Magazine and Journal of Science. 1911;22:840-54.

6. Hulst RA, Klein J, Lachmann B. Gas embolism: pathophysiology and treatment. Clin Physiol Funct Imaging. 2003;23:237-46.

7. Bouck GR. Etiology of gas bubble disease. Transactions of the American Fisheries Society. 1980;109:703-7.

8. Tibbles PM, Edelsberg JS. Hyperbaric-oxygen therapy. N Engl J Med. 1996;334:1642-8.

9. Gabb G, Robin ED. Hyperbaric oxygen. A therapy in search of diseases. Chest. 1987:92:1074-82.

10. Leach R, Rees $P$, Wilmshurst P. Hyperbaric oxygen therapy. BMJ. 1998;317:1140-3.

11. Balestra C, Germonpré P, Poortmans JR, et al Serum erythropoietin levels in healthy humans after a short period of normobaric and hyperbaric oxygen breathing: the "normobaric oxygen paradox". J Appl Physiol. 2006;100:512-8.

12. Boyle R, Kesaris $P$, Hunter MCW. Letters and papers of Robert Boyle: a guide to the manuscripts and microfilm. Greenwood Pub Group; 1992.

13. Boyle R. The general history of the air London. Printed for Awnsham and John Churchill; 1692.

14. Dalton J. On the constitution of mixed gases, on the force of steam of vapour from water and other liquids in different temperatures, both in a Torricellia vacuum and in air; on evaporation; and on the expansion of gases by heat. Memoirs, Literary and Philosophical Society of Manchester. 1802:5:536-602.

15. Brown DR, Davis NL, Lepawsky M, et al. A multicenter review of the treatment of major truncal necrotizing infections with and without hyperbaric oxygen therapy. Am J Surg. 1994;167:485-9.

16. Clark L, Moon R. Hyperbaric oxygen in the treatment of life-threatening soft-tissue infections. Respir Care Clin N Am. 1999:5:203-19.

17. Korhonen $\mathrm{K}$, editor. Hyperbaric oxygen therapy in acute necrotizing infections. With a special reference to the effects on tissue gas tensions. Ann Chir Gynaecol. 2000;89(Suppl 214):7-36.

18. Borriello G, Werner E, Roe F, et al. Oxygen limitation contributes to antibiotic tolerance of Pseudomonas aeruginosa in biofilms. Antimicrob Agents Chemother. 2004:48:2659-64

19. Myers RA. Hyperbaric oxygen therapy for trauma: crush injury, compartment syndrome, and other acute traumatic peripheral ischemias. Int Anesthesiol Clin. 2000;38:139-51.

20. Zamboni WA, Roth AC, Russell RC, et al. Morphologic analysis of the microcirculation during reperfusion of ischemic skeletal muscle and the effect of hyperbaric oxygen. Plast Reconstr Surg. 1993;91:1110-23.

21. Isik A, Peker $K$, Gursul $C$, et al. The effect of ozone and naringin on intestinal ischemia/reperfusion injury in an experimental model. Int $J$ Surg. 2015;21:38-44.

22. Daniel RA, Cardoso VK, Góis Jr E, et al. Evaluation of pulmonary reperfusion injury in rats undergoing mesenteric ischemia and reperfusion and protective effect of postconditioning on this process. Rev Bras Cir Cardiovasc. 2015;30:533-7.

23. Andreadou I, lliodromitis EK, Rassaf $\mathrm{T}$, et al. The role of gasotransmitters $\mathrm{NO}, \mathrm{H} 2 \mathrm{~S}$ and $\mathrm{CO}$ in myocardial ischaemia/reperfusion injury and cardioprotection by preconditioning, postconditioning and remote conditioning. Br J Pharmacol. 2015;172:1587-606.

24. Neuman TS, Thom SR. Physiology and medicine of hyperbaric oxygen therapy. Philadelphia: Saunders/Elsevier; 2008.

25. Aug G-B. Le mecanisme Cartesien et la physiologie au XVIle siecle. Isis. 1914:2:37-89.

26. Manley $G$. The weather and diseases: some eighteenth-century contributions to observational meteorology. Notes and Records of the Royal Society of London. 1952:9:300-7.

27. Brimblecombe P. Air pollution in industrializing england. Journal of the Air Pollution Control Association. 1978;28:115-8

28. Arbuthnot J. An essay concerning the effects of air on human bodies: $J$. Tonson; 1733.

29. Sprat T. The history of the Royal Society of London: for the improving of natural knowledge. J. Knapton; 1734

30. Henshaw N. Aërochalinos. London: editor desconocido; 1667.

31. Sternbach GL, Varon J. The discovery and rediscovery of oxygen. Emerg Med J. 2005;28:221-4.

32. Williams CT. Aero-therapeutics or, the treatment of lung diseases by climate; Being the Lumleian Lectures for 1893 delivered before the Royal College of Physicians, with an address on the High Altitudes of Colorado. Macmillan and Company; 1894. 
33. Djerassi C, Hoffmann R. From oxygen: a play in two acts. The Kenyon Review. 2001;23:221-36.

34. Priestley J. The discovery of oxygen. Part 1: experiments. WF Clay; 1894.

35. Bowden ME, Rosner L. Joseph Priestley, radical thinker: a catalogue to accompany the exhibit at the Chemical Heritage Foundation Commemorating the $200^{\text {th }}$ anniversary of the death of Joseph Priestley. Chemical Heritage Foundation; 2005.

36. Riera i Tuèbols $\mathrm{S}$. La teoria del flogist, la química pneumàtica i Antoine Laurent Lavoisier. Ciència 2a època. 2014;50:36-42.

37. Bert P, Hitchcock MA, Hitchcock FA. Barometric pressure. College Book Company; 1943.

38. Davies JV. The tunnel construction of the Hudson and Manhattan Railroad Company. Proc Am Philos Soc. 1910;49:164-87.

39. Smith $\mathrm{AH}$. The effects of high atmospheric pressure: including the caisson disease. Eagle Book and Job Print; 1873. 53 p.

40. Butler W. Caisson disease during the construction of the Eads and Brooklyn Bridges: a review. Undersea Hyperb Med. 2004 Winter;31:445-59.

41. McCullough D. The Great Bridge: the epic story of the building of the Brooklyn Bridge. Nueva York: Simon and Schuster; 2012. 605 p.

42. Vernon $\mathrm{H}$. The solubility of air in fats, and its relation to caisson disease. Proceedings of the Royal Society of London Series B, Containing Papers of a Biological Character. 1907;79:366-71.

43. Boycoh A, Damant G. Experiments on the influence of fatness on susceptibility to caisson disease. J Hygiene. 1908;8:445-56. Erdmann W, Bruley DF. Oxygen transport to jssue XIV. Springer US; 2012.

44. Aldrich C. Compressed-air illness, caisson disease. Int Clin. 1900; 10:73-88.

45. Boycott A, Haldane J. The effects of low atmospheric pressures on respiration. J Physiol. 1908;37:355

46. Thomson WA. The physiology of deep-sea diving. BMJ. 1935;2:208.

47. Gordon J, Heacock C. Roentgenologic demonstration of localized gas in caisson disease. JAMA. 1940;114:570-1.

48. Powers JG, Higham C, Broussard $K$, et al. Wound healing and treating wounds: chronic wound care and management. JAAD. 2016;74:607-25.

49. Feldmeier J, Hopf $\mathrm{H}$, Warriner III R, et al. UHMS position statement: topical oxygen for chronic wounds. Undersea Hyperb Med. 2005;32:157.

50. Bishop AJ. Diabetic lower extremity ulcers and hyperbaric oxygen therapy. J Endocrinol Diab. 2015;2:1-5

51. Stoekenbroek R, Santema T, Legemate D, et al. Hyperbaric oxygen for the treatment of diabetic foot ulcers: a systematic review. Eur J Vasc Endovasc Surg. 2014;47:647-55.

52. Fagher K, Katzman P, Löndahl M. Hyperbaric oxygen therapy reduces the risk of QTc interval prolongation in patients with diabetes and hardto-heal foot ulcers. J Diabet Complications. 2015;29:1198-202.

53. Doctor N, Pandya S, Supe A. Hyperbaric oxygen therapy in diabetic foot. J Postgrad Med. 1992;38:112.

54. Elraiyah T, Tsapas A, Prutsky G, et al. A systematic review and meta-analysis of adjunctive therapies in diabetic foot ulcers. J Vasc Surg Cases. 2016;63:46S-58S. e2.

55. Murphy-Lavoie H, Butler F, Hagan C. Central retinal artery occlusion treated with oxygen: a literature review and treatment algorithm. Undersea Hyperb Med. 2012;39:943.

56. Vingolo EM, Rocco M, Grenga P, et al. Slowing the degenerative process, long lasting effect of hyperbaric oxygen therapy in retinitis pigmentosa. Graefes Arch Clin Exp Ophthalmol. 2008;246:93-8.

57. Körpinar Ş, Alkan Z, Yiğit Ö, et al. Factors influencing the outcome of idiopathic sudden sensorineural hearing loss treated with hyperbaric oxygen therapy. Eur Arch Otorhinolaryngol. 2011;268:41-7.

58. Holy R, Navara M, Dosel P, et al. Hyperbaric oxygen therapy in idiopathic sudden sensorineural hearing loss (ISSNHL) in association with combined treatment. Undersea Hyperb Med. 2011;38:137.

59. Plein CT, Harounian J, Floyd E, et al. A systematic review of eligibility and outcomes in tinnitus trials reassessment of tinnitus guideline. Otolaryngol Head Neck Surg. 2016;154:24-32.

60. Cavallazzi G, Pignataro L, Capaccio P, editores. Italian experience in hyperbaric oxygen therapy for idiopathic sudden sensorineural hearing loss. International Joint Meeting on Hyperbaric and Underwater Medicine 1996.
61. Stachler RJ, Chandrasekhar SS, Archer SM, et al. Clinical practice guideline sudden hearing loss. Otolaryngol Head Neck Surg. 2012;146(3 Suppl):S1-S35.

62. Mukherjee A, Raison M, Sahni T, et al. Intensive rehabilitation combined with $\mathrm{HBO} 2$ therapy in children with cerebral palsy: a controlled longitudinal study. Undersea Hyperb Med. 2014;41:77-85.

63. Chen S-Y, Huang E, Wang V, et al. Improvement of clinical outcome and cerebral perfusion in a patient of atherosclerotic cerebral infarction after repetitive hyperbaric oxygen treatment - a case report and literature review. Undersea Hyperb Med. 2011;38:375.

64. Shen M, He J, Cai J, et al. Hydrogen as a novel and effective treatment of acute carbon monoxide poisoning. Med Hypotheses. 2010;75:235-7.

65. Valadão J, Pearl J, Verma S, et al. Hyperbaric oxygen treatment for post-radiation central nervous system injury: a retrospective case series. Undersea Hyperb Med. 2014:41:87-96.

66. Weaver LK, Valentine KJ, Hopkins RO. Carbon monoxide poisoning: risk factors for cognitive sequelae and the role of hyperbaric oxygen. Am J Respir Crit Care Med. 2007;176:491-7.

67. Peng Z, Wang S, Huang $X$, et al. Effect of hyperbaric oxygen therapy on patients with herpes zoster. Undersea Hyperb Med. 2012;39:1083.

68. Freiberger JJ, Padilla-Burgos R, Chhoeu AH, et al. Hyperbaric oxygen treatment and bisphosphonate-induced osteonecrosis of the jaw: a case series. Oral Maxillofac Surg. 2007;65:1321-7.

69. Bent S, Bertoglio K, Ashwood P, et al. Brief report: hyperbaric oxygen therapy (HBOT) in children with autism spectrum disorder: a clinical trial. Autism Dev Disord. 2012:42:1127-32.

70. Al-Waili NS, Butler GJ, Beale J, et al. Hyperbaric oxygen and malignancies: a potential role in radiotherapy, chemotherapy, tumor surgery and phototherapy. Med Sci Monit. 2005;11:RA279-RA289.

71. Fredman R, Wise I, Friedman T, et al. Skin-sparing mastectomy flap ischemia salvage using urgent hyperbaric chamber oxygen therapy: a case report. Undersea Hyperb Med. 2014;41:145-7.

72. Thom SR. Hyperbaric oxygen - its mechanisms and efficacy. Plast Reconstr Surg. 2011;127(Suppl 1):131S.

73. Khandelwal S, Wall J, Kaide C, et al. Case report: successful use of hyperbaric oxygen therapy for a complete scalp degloving injury. Undersea Hyperb Med. 2008;35:441-5.

74. Chong KT, Hampson NB, Corman JM. Early hyperbaric oxygen therapy improves outcome for radiation-induced hemorrhagic cystitis. Urology. 2005:65:649-53.

75. Hassan Z, Mullins RF, Friedman BC, et al. Treating necrotizing fasciitis with or without hyperbaric oxygen therapy. Undersea Hyperb Med. 2010;37:115.

76. Mortensen CR. Hyperbaric oxygen therapy. Curr Anaesth Crit Care. 2008;19:333-7.

77. Bakker DJ. Clostridial myonecrosis (gas gangrene). Undersea Hyperb Med. 2012;39:731.

78. Jordan JE, Zhao ZQ, Vinten-Johansen J. The role of neutrophils in myocardial ischemia-reperfusion injury. Cardiovasc Res. 1999;43:860-78.

79. Weyker PD, Webb CA, Kiamanesh D, et al. Lung ischemia reperfusion injury: a bench-to-bedside review. Semin Cardiothorac Vasc Anesth. 2013;17:28-43.

80. Yu WK, Chen YW, Shie HG, et al. Hyperbaric oxygen therapy as an adjunctive treatment for sternal infection and osteomyelitis after sternotomy and cardiothoracic surgery. J Cardiothorac Surg. 2011;6:1.

81. McGrath T, Hamilton R. Hyperbaric oxygen in the treatment of venomous snake bites. Undersea Hyperb Med. 2010;37:393-4.

82. Quinn DK, McGahee SM, Politte LC, et al. Complications of carbon monoxide poisoning: a case discussion and review of the literature. Prim Care Companion J Clin Psychiatry. 2009;11:74-9.

83. Cooper JS, Allinson P, Keim L, et al. Hyperbaric oxygen: a useful adjunct for purpura fulminans: case report and review of the literature. Undersea Hyperb Med. 2014;41:51-7.

84. Graffeo C, Dishong W. Severe blood loss anemia in a Jehovah's Witness treated with adjunctive hyperbaric oxygen therapy. Am J Emerg Med. 2013;31:756. e3-4

85. Hart G, Lennon P, Strauss M. Hyperbaric oxygen in exceptional acute blood-loss anemia. Undersea Hyperb Med. 1987;2:205-10.

86. Pineda JF, Ortiz CG, Miguel G de J, et al. Improvement in serum anti-Müllerian hormone levels in infertile patients after hyperbaric oxygen (preliminary results). JBRA Assisted Reproduction. 2015;19:87-90. 